\title{
DETERMINAÇÃO DE ARSÊNIO EM AMOSTRAS DA CADEIA PRODUTIVA DE FRANGOS DE CORTE POR ESPECTROMETRIA DE ABSORÇÃO ATÔMICA COM FORNO DE GRAFITE
}

\author{
Amália G. G. Dionísio*, Mário H. Gonzalez e Joaquim A. Nóbrega \\ Departamento de Química, Universidade Federal de São Carlos, CP 676, 13560-970 São Carlos - SP, Brasil
}

Recebido em 5/1/10; aceito em 2/8/10; publicado na web em 9/11/10

\begin{abstract}
DETERMINATION OF ARSENIC IN CHICKEN AND CHICKEN PRODUCTION-RELATED SAMPLES USING GRAPHITE FURNACE ATOMIC ABSORPTION SPECTROMETRY. Chicken meat is largely consumed in human nutrition and it is produced in extremely large scale in some countries, including Brazil. In this work graphite furnace atomic absorption spectrometry was used for determination of arsenic in chicken and chicken production-related samples. These samples were digested employing a microwaveassisted procedure in closed vessels using a $7 \mathrm{~mol} \mathrm{~L}^{-1}$ nitric acid solution plus concentrated hydrogen peroxide. The concentration range of total As determined in chicken production-related samples varied from 1.30 to $29.8 \mathrm{mg} \mathrm{kg}^{-1}$ of As. The detection and quantification limits reached were 0.055 and $0.182 \mathrm{mg} \mathrm{kg}^{-1}$, respectively $(\mathrm{n}=15)$.
\end{abstract}

Keywords: chicken; arsenic; graphite furnace.

\section{INTRODUÇÃO}

Arsênio pode ser encontrado em diversas formas químicas na natureza, incluindo espécies orgânicas e inorgânicas, como resultado de sua participação em processos biológicos, químicos e aplicações industriais. $\mathrm{O}$ arsênio apresenta um comportamento químico diversificado no ambiente natural e ocorre em quatro estados de oxidação: arsenato $(+5)$, arsenito $(+3)$, arsina $(-3)$ e na forma elementar $(0)$. Contudo, as espécies solúveis geralmente ocorrem nos estados de oxidação +3 e +5. As toxicidades dos compostos de arsênio diminuem na seguinte sequência: arsina (-3), derivados orgânicos de arsina, arsênio inorgânico (+3), arsênio orgânico (+3), arsênio inorgânico (+5), compostos orgânicos pentavalentes, compostos de arsênio e arsênio elementar. ${ }^{1}$

A produção de aves domésticas tem se tornado um grande atrativo no mercado mundial e o Brasil ocupa uma posição de destaque nesse mercado, atuando como um grande exportador de carne de frango. $\mathrm{O}$ consumo de carne de frango de corte tem apresentado um crescimento considerável nos últimos anos. ${ }^{2}$

O êxito da cadeia produtiva do frango de corte é dependente de cuidados com a alimentação das aves. Como parte das estratégias nutricionais, eventualmente pode-se utilizar um estimulante organoarsênico denominado roxarsone (i.e. ácido 3-nitro-4-hidroxifenilarsênico) para a alimentação das aves visando garantir uma melhor pigmentação da carne, promover uma aceleração do crescimento, aumentar o peso das aves e eliminar os parasitas causadores de doenças. Esse composto é considerado relativamente benigno e pode ser facilmente convertido nas formas mais tóxicas desse elemento, que são as formas inorgânicas As(III) e As(V). ${ }^{3}$ Trabalhos na literatura mostram que um micro-organismo do gênero Clostridium é capaz de converter em menos de 10 dias o roxarsone em arsenato, podendo esse ser facilmente lixiviado para águas subterrâneas. ${ }^{4}$

Esse composto apresenta um ciclo que se inicia na alimentação das aves, sendo que em condições anaeróbicas origina o arsênio na forma inorgânica, que pode ficar alojado tanto na carne do frango ou ser excretado na cama de frango. A cama de frango, apesar do uso proibido, pode ser utilizada na alimentação bovina e na forma de adubos para a agricultura por conter altos níveis de ureia e, dessa

*e-mail: amaliaggd@yahoo.com.br forma, pode contaminar o ambiente e uma série de produtos de alto consumo na cadeia alimentar humana.

De acordo com estudos realizados, o consumo humano da carne de frango pode implicar em ingestão média diária entre 1,3 a 5,2 $\mu \mathrm{g}$ de As por dia. ${ }^{3}$ Salienta-se que a contaminação do organismo humano por esse elemento não ocorre somente pela ingestão de aves, uma vez que também pode ocorrer por meio de água contaminada, uso de pesticidas e herbicidas à base de arsênio, materiais semicondutores, eletrônicos, mineração, produção de vidros, plásticos e produtos químicos.

Um problema encontrado na determinação de arsênio é que a concentração do analito na amostra geralmente é baixa, sendo necessário empregar técnicas com alta sensibilidade. A espectrometria de absorção atômica com atomização eletrotérmica em forno de grafite (GF AAS) oferece a vantagem de proporcionar alta sensibilidade para baixos volumes de amostra. Os atomizadores eletrotérmicos proporcionam um aumento na sensibilidade devido à eficiente atomização da amostra sob altas temperaturas, ao maior tempo de residência dos átomos no caminho óptico e ao menor volume de observação comparativamente ao atomizador com chama. Além disso, a alíquota de amostra selecionada é totalmente transferida para o atomizador, contrariamente ao que ocorre em sistemas com introdução de amostra por nebulização pneumática. .7 $^{5-7}$

Considerando a presença deste elemento em baixas concentrações, o presente trabalho buscou avaliar a ocorrência de arsênio em amostras relacionadas ao ciclo produtivo de frango de corte, empregando soluções de ácido nítrico diluído para a digestão das amostras e a determinação do analito por GF AAS.

\section{PARTE EXPERIMENTAL}

\section{Amostras}

As amostras utilizadas foram coletadas em granjas e estão relacionadas aos $1^{\circ}, 15^{\circ}, 30^{\circ}$ e $45^{\circ}$ dias do ciclo da cadeia produtiva do frango de corte. Esses intervalos de coleta foram sugeridos pelos produtores, visando obter uma visão global da fase inicial da criação até o momento de abate dos frangos. As amostras denominadas A e B foram coletadas em pontos distintos da granja. Coletaram-se amostras de cama de frango e penas de frango. Diferentes tipos de rações de 
frango para as fases de engorda, postura e crescimento também foram adquiridas no Brasil e no exterior. Também foi determinado o teor de arsênio em coxa, pele e peito de frango em 4 animais.

A exatidão do método foi avaliada pelo material de referência certificado de fígado bovino NIST 1577b (National Institute of Standards and Technology, Gaithersburg, MD, EUA).

\section{Materiais e equipamentos}

Para secagem das amostras foi utilizado liofilizador, modelo E-C MicroModulyo. As amostras secas foram cominuídas em moinho criogênico Spex CertiPrep modelo 6750 (Metuchen, NJ, EUA) para homogeneização e, consequentemente, melhor representatividade a partir de pequenas massas do material.

Posteriormente, as amostras moídas foram digeridas em forno de radiação micro-ondas com cavidade modelo Ethos (Milestone, Sorisole, Itália) usando frascos fechados de PFA.

Utilizou-se um espectrômetro de absorção atômica com atomização eletrotérmica em forno de grafite - GTA 100 SpectrAA - 800 (Varian), equipado com corretor com base no efeito Zeeman transversal e aquecimento longitudinal, ultralâmpada de catodo oco de arsênio (corrente elétrica aplicada de $10 \mathrm{~mA}$, resolução espectral de $0,2 \mathrm{~nm}$ e comprimento de onda de 193,7 nm) para as determinações de arsênio.

\section{Soluções e reagentes}

Todos os frascos, ponteiras e vidrarias utilizados foram previamente descontaminados em banhos contendo $10 \%$ (v/v) de $\mathrm{HNO}_{3}$ por $24 \mathrm{~h}$.

As soluções foram preparadas empregando reagentes de alta pureza analítica e água destilada-desionizada produzida em sistema Milli-Q (Millipore, Bedford, MA, EUA). As soluções ácidas foram preparadas utilizando $\mathrm{HNO}_{3}$ (Merck, Darmstadt, Alemanha) purificado no sistema de sub-destilação (SubPur, Milestone). Como agente oxidante auxiliar foi utilizado $30 \% \mathrm{~m} \mathrm{v}^{-1} \mathrm{H}_{2} \mathrm{O}_{2}$ Synth (LabSynth, São Paulo).

As soluções de calibração necessárias para obtenção da curva analítica e determinação de arsênio por GFAAS foram preparadas a partir de diluições de solução estoque contendo $1000 \mathrm{mg} \mathrm{L}^{-1}$ de arsênio. Solução de nitrato de paládio na concentração de $1000 \mathrm{mg} \mathrm{L}^{-1}$ (Titrisol Merck, Darmstadt, Alemanha) foi empregada como modificador químico.

Todas as medidas e procedimentos foram realizados em triplicata.

\section{Procedimento de digestão}

As amostras de ração, cama de frango, penas e carnes de frango foram digeridas usando-se o mesmo programa de aquecimento. Massas de $0,250 \mathrm{~g}$ de amostras foram pesadas e transferidas para os frascos de digestão e, posteriormente, decompostas em forno micro-ondas com cavidade usando 5,0 mL de solução 7,0 $\mathrm{mol} \mathrm{L}^{-1} \mathrm{HNO}_{3}$ e $3,0 \mathrm{~mL}$ de $\mathrm{H}_{2} \mathrm{O}_{2}$ concentrado. O programa de aquecimento empregado consistia de 6 etapas: 3 min aplicando-se $300 \mathrm{~W} ; 1$ min sem aplicação de potência; 4 min aplicando-se $500 \mathrm{~W} ; 3$ min aplicando-se $650 \mathrm{~W} ; 3$ min aplicando-se $1000 \mathrm{~W}$ e, 15 min sob ventilação. Os digeridos foram transferidos para frascos volumétricos e diluídos para $30,0 \mathrm{~mL}$ com água desionizada. As temperaturas máximas obtidas durante a digestão foram de $185^{\circ} \mathrm{C}$.

\section{Procedimento para avaliação da exatidão}

A exatidão do procedimento foi avaliada pelo método de adição e recuperação do analito e também pela determinação de arsênio em um material de referência certificado de fígado bovino (SRM 1577b). Assim, adicionaram-se alíquotas de 40 e $20 \mu \mathrm{g} \mathrm{L}^{-1}$ de As nos digeridos das amostras de pena 30B e pena 45B, respectivamente. Em seguida, realizou-se a determinação de As por GF AAS.

Por outro lado, a exatidão do procedimento de preparo de amostra foi avaliada adicionando-se alíquotas de 40 e $20 \mu \mathrm{g} \mathrm{L}^{-1}$ às amostras de pena de frango $30 \mathrm{~B}$ e de ração $45 \mathrm{~B}$, respectivamente. Em seguida, as amostras foram submetidas ao processo de digestão assistido por radiação micro-ondas. Posteriormente, determinou-se As empregando GF AAS visando avaliar a recuperação do analito. Esse procedimento buscou avaliar se havia perdas de arsênio por volatilização durante o preparo das amostras.

A adição de níveis distintos de As em amostras diferentes possibilitou uma avaliação mais completa da robustez do procedimento.

\section{Procedimento para determinação de As nas amostras}

Os teores totais de arsênio nas amostras foram determinados por GF AAS. Uma solução contendo $50 \mu \mathrm{g} \mathrm{L}^{-1}$ de As em meio de $0,1 \%$ v/v $\mathrm{HNO}_{3}$ foi empregada para a obtenção das curvas de temperatura de pirólise e atomização e, a partir dos dados obtidos, estabeleceu-se o programa de aquecimento descrito na Tabela 1.

Tabela 1. Programa de aquecimento do GFAAS para a determinação de arsênio

\begin{tabular}{lccc}
\hline Etapa & $\begin{array}{c}\text { Temperatura } \\
\left({ }^{\circ} \mathrm{C}\right)\end{array}$ & $\begin{array}{c}\text { Tempo }(\mathrm{s}) \\
(\text { rampa, patamar })\end{array}$ & $\begin{array}{c}\text { Vazão do gás } \\
\left(\mathrm{L} \mathrm{min}{ }^{-1}\right)\end{array}$ \\
\hline Secagem & 90 & 5,40 & 3,0 \\
Secagem & 120 & 10,5 & 3,0 \\
Pirólise & 700 & 5,2 & 3,0 \\
Atomização & 2300 & 1,2 & 0 \\
Limpeza & 2800 & 2,1 & 3,0 \\
\hline
\end{tabular}

\section{RESULTADOS E DISCUSSÃO}

\section{Curvas de temperatura de pirólise e atomização para As}

As temperaturas de pirólise e atomização foram estabelecidas a partir das curvas obtidas experimentalmente em meio de $\mathrm{HNO}_{3} \mathrm{e}$ Pd. A opção de trabalhar com esse modificador está de acordo com estudos realizados por Husáková et al. e visa minimizar as interferências espectrais causadas pelos elevados teores de fósforo presentes nas amostras. ${ }^{8}$ Como a maioria das formas de arsênio apresenta alta volatilidade optou-se por utilizar Pd como modificador químico. Welz e Sperling apontaram que nitrato de paládio estabiliza termicamente formas orgânicas e inorgânicas de arsênio. ${ }^{6}$ As curvas de temperatura de pirólise e atomização foram geradas experimentalmente pela variação gradual de temperatura em intervalos de $100{ }^{\circ} \mathrm{C}$ (Figura 1).

O máximo sinal de absorbância integrada para a etapa de pirólise sem perdas do analito e usando-se modificador químico ocorreu em temperatura de $700{ }^{\circ} \mathrm{C}$. Acima desta temperatura ocorreu queda no sinal de absorbância, indicando perdas do analito por volatilização. Fixando-se esse valor para a temperatura de pirólise, executou-se um experimento para estabelecer o máximo sinal de absorbância na etapa de atomização, que ocorreu em $2300^{\circ} \mathrm{C}$. Esses resultados estão concordantes com a literatura, visto que para vários trabalhos empregando esse mesmo modificador químico a temperatura de pirólise estabelecida variou entre 700 e $1200^{\circ} \mathrm{C}$, enquanto que a temperatura de atomização variou entre 2100 e $2500^{\circ} \mathrm{C} .{ }^{9-14}$

\section{Determinação de As: parâmetros de desempenho}

A partir do programa de aquecimento estabelecido e dos dados experimentais foi possível calcular a massa característica para o 


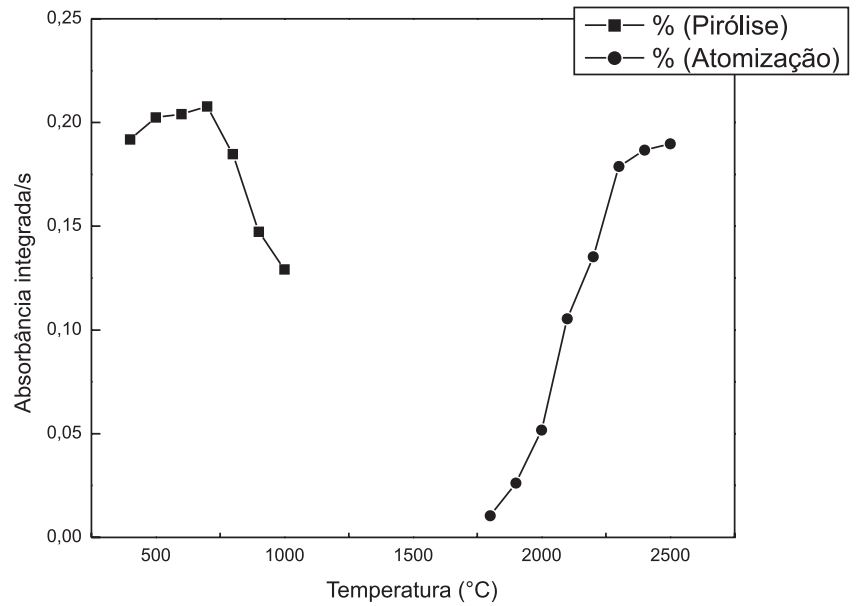

Figura 1. Curvas de temperatura de pirólise e de atomização para As $50 \mu \mathrm{g} \mathrm{L}^{-1}$ em meio de $\mathrm{HNO}_{3} 0,1 \% v v^{-1}$ e paládio $1000 \mathrm{mg} \mathrm{L}^{-1}$ como modificador químico

analito. Frequentemente esse parâmetro é empregado para avaliar a condição de operação do instrumento. Neste trabalho, foi empregado um forno de grafite com aquecimento longitudinal e a massa característica determinada foi de 23 pg, que é um valor comparável com os da literatura (ao redor de $15 \mathrm{pg}$ ). ${ }^{6}$ Esses valores de massa característica diferem para cada tipo de forno, devido às dimensões do tubo e ao gradiente de temperatura que ocorre no interior do tubo de grafite durante o aquecimento.

O limite de detecção (LOD), que é calculado como 3 vezes o valor do desvio padrão do branco analítico dividido pelo coeficiente angular da curva analítica de calibração, e o limite de quantificação (LOQ), que é calculado como 10 vezes o valor do desvio padrão do branco analítico dividido pelo coeficiente angular da curva analítica de calibração, foram determinados. O LOD foi de $0,055 \mathrm{mg} \mathrm{kg}^{-1}$ e o LOQ foi de $0,182 \mathrm{mg} \mathrm{kg}^{-1}$.

A repetibilidade foi de $0,8 \%$ para uma concentração de $40 \mu \mathrm{g}$ $\mathrm{L}^{-1}$ de As $(\mathrm{n}=15)$.

A eficiência do procedimento de preparo de amostra foi avaliada utilizando-se material de referência certificado de fígado bovino, sendo que uma massa de $0,250 \mathrm{~g}$ foi submetida ao mesmo procedimento de digestão adotado para as amostras. O teor de arsênio desse material, i.e. NIST $1577 \mathrm{~b}$, é fornecido como um valor de referência de $0,05 \mathrm{mg} \mathrm{kg}^{-1}$. O teor determinado de As foi de 0,059 $\pm 0,02$ (média \pm desvio padrão, para $\mathrm{n}=3$ ) indicando uma recuperação de $118 \%$, calculado a partir do valor de referência.

Foram realizados dois experimentos de adição e recuperação. No primeiro, para avaliação das medidas por GF AAS, teores conhecidos de As foram introduzidos em dois digeridos. As recuperações para os digeridos de penas de frango 30B foi de $90,2 \%$ e para 45B foi de $104,3 \%$. Pode-se concluir que os teores recuperados são aceitáveis e possibilitam inferir que a exatidão da medida por GF AAS está adequada, considerando-se os baixos teores de arsênio adicionados.

No segundo experimento, a adição da solução de arsênio foi feita previamente à digestão. Nesses casos, as recuperações foram de 91,5 e $105,5 \%$ para as amostras de penas de frango 30B e 45B, respectivamente, atestando-se dessa forma que não ocorreram perdas de arsênio no procedimento de preparo de amostra em frascos fechados e aquecimento assistido por radiação micro-ondas.

\section{Determinação de arsênio nas amostras do ciclo produtivo de frango de corte}

As determinações foram realizadas por GF AAS em digeridos preparados usando solução de ácido nítrico $1+1(\mathrm{v} / \mathrm{v})$, i.e., $7 \mathrm{~mol} \mathrm{~L}{ }^{-1}$. A curva analítica de calibração foi obtida usando-se soluções contendo 0,$10 ; 25 ; 50 ; 75 ; 100$ e $125 \mu \mathrm{g} \mathrm{L}^{-1}$ de As. Obteve-se um coeficiente de correlação linear de 0,9981 .

\section{Amostras de ração}

Os teores determinados de arsênio para as amostras de ração de frango estão apresentados na Tabela 2.

Tabela 2. Teores determinados de arsênio em amostras de ração

\begin{tabular}{cc}
\hline Amostra & As $\left(\mathrm{mg} \mathrm{kg}^{-1}\right)$ \\
\hline Ração de crescimento & $0,35 \pm 0,01$ \\
Ração de postura I & $0,40 \pm 0,04$ \\
Ração de engorda I & $0,42 \pm 0,03$ \\
Ração granulada & $0,40 \pm 0,01$ \\
Ração de crescimento & $2,43 \pm 0,06$ \\
Ração para aves & $<0,069$ \\
Ração de produção poedeiras & $<0,069$ \\
Ração de frango inicial & $<0,069$ \\
Ração de postura & $0,46 \pm 0,01$ \\
Ração de crescimento & $0,54 \pm 0,06$ \\
Ração de aves terminação & $<0,069$ \\
Ração granulada & $0,44 \pm 0,01$ \\
Ração & $0,25 \pm 0,03$ \\
\hline
\end{tabular}

*média \pm desvio padrão, $\mathrm{n}=3$

Pode-se observar que algumas amostras continham concentrações elevadas de arsênio, o que pode estar relacionado com o uso do estimulante à base de arsênio, sendo que a concentração adicionada nas rações pode variar de 22,7 até 45,4 g por tonelada. ${ }^{15}$ Por outro lado, como a utilização desse estimulante visa promover o crescimento e garantir uma melhor pigmentação da carne do frango, acredita-se que isso possa explicar os teores encontrados nas amostras de engorda, crescimento e postura. Observa-se que os teores em algumas amostras são similares, contudo, outros aspectos devem ser considerados, como o uso de matérias-primas e processamentos similares na fabricação dessas rações. Esses aspectos vêm alertando as agências de vigilância sanitária sobre os teores encontrados de arsênio em vários tipos de amostras, inclusive amostras alimentícias.

Com relação aos teores de As presentes nas amostras de ração de diversas procedências, observou-se que as amostras de ração tanto para frangos como para poedeiras apresentaram teores de arsênio inferiores ao LOD, o que provavelmente pode ser explicado considerando-se as funções do arsênio como estimulante e o modo de criação desses animais. Observou-se um teor elevado de arsênio em uma das amostras, "ração de crescimento". Sabia-se previamente que havia sido propositalmente adicionado o estimulante organoarseniacal (roxarsone) nessa amostra, por isso esse elevado teor de arsênio presente na amostra. Contudo, essas discrepâncias entre os resultados devem ser atribuídos a outros aspectos, como fornecedor de ração, matéria-prima utilizada no preparo dessas rações e processo de fabricação. Além disso, sabe-se que as concentrações de arsênio nas rações podem variar de país para país. ${ }^{3}$

\section{Amostras de penas e cama de frango}

Os teores determinados para as amostras de penas de frango estão apresentados na Tabela 3 . 
Tabela 3. Teores determinados de arsênio em amostras de penas de frango e cama de frango

\begin{tabular}{cc}
\hline Amostra & As $\left(\mathrm{mg} \mathrm{kg}^{-1}\right)$ \\
\hline Pena 15 A & $1,98 \pm 0,09$ \\
Pena 15 B & $2,14 \pm 0,13$ \\
Pena 30 A & $1,43 \pm 0,02$ \\
Pena 30 B & $1,30 \pm 0,01$ \\
Pena 45 A & $1,96 \pm 0,13$ \\
Pena 45 B & $2,14 \pm 0,25$ \\
Cama de frango 1 A & $29,8 \pm 2,75$ \\
Cama de frango 1 B & $26,8 \pm 1,77$ \\
Cama de frango 15 A & $12,5 \pm 0,89$ \\
Cama de frango 15 B & $36,7 \pm 1,96$ \\
Cama de frango 30 A & $6,06 \pm 0,14$ \\
Cama de frango 30 B & $15,9 \pm 0,70$ \\
Cama de frango 45 A & $22,8 \pm 0,34$ \\
Cama de frango 45 B & $14,6 \pm 1,01$ \\
\hline
\end{tabular}

*média \pm desvio padrão, $\mathrm{n}=3$

Constatou-se a presença de arsênio em todas as amostras, podendo-se inferir que eventualmente estão ocorrendo duas frentes de contaminação, uma do animal e outra do ambiente. Ambas as frentes de contaminação têm potencial para inserção na cadeia alimentar humana. $\mathrm{O}$ aspecto mais grave está relacionado ao final de ciclo, pois quando o frango vai para o abate essas penas são queimadas ao ar livre ocasionando uma contaminação ambiental. Há casos nos quais as penas são trituradas, misturadas com outros insumos e empregadas como ração animal.

A cama de frango é uma mistura de substrato de excrementos, penas e restos de rações. Pode-se constatar que ocorre uma variação significativa dos teores de arsênio, de 6,06 $\pm 0,14$ até 36,7 $\pm 1,96 \mathrm{mg}$ $\mathrm{kg}^{-1}$. Como se sabe, essa cama de frango analisada é composta de serragem e capim e o arsênio também é utilizado como conservante de madeira. Assim, pode-se supor que parte do arsênio determinado seja proveniente da serragem de madeira e isso poderia explicar esses valores tão discrepantes. ${ }^{16}$ Um possível problema decorrente desses teores relativamente elevados de arsênio na cama de frango é que, apesar da utilização ser proibida por apresentar elevados teores de ureia, em alguns casos esse material é utilizado como adubo agrícola ou até mesmo na alimentação de ruminantes. Outra forma de contaminação poderia ser através da eliminação dos excrementos dos frangos na cama de frango, provenientes da alimentação à base de compostos contendo arsênio que, como consequência, acaba contaminando o solo e as águas subterrâneas.

Deve-se ainda ressaltar que mesmo não sendo o foco deste estudo, determinou-se arsênio em diferentes amostras de carnes de frango e os teores encontrados estavam próximos aos limites de detecção, indicando que não há a presença de arsênio no produto final para consumo humano.

\section{CONCLUSÃO}

O procedimento desenvolvido com o emprego de digestão ácida assistida por radiação micro-ondas em frascos fechados foi eficiente com relação às eventuais perdas do analito e contaminação. O emprego de ácido nítrico diluído $1+1$ (v/v) para a digestão das amostras foi comprovado como uma alternativa viável e recomendável, reduzindo o consumo de reagentes e, consequentemente, gerando brancos analíticos em torno de $0,038 \mu \mathrm{g} \mathrm{L}-1$ e limites de detecção e de quantificação de 0,055 e $0,182 \mathrm{mg} \mathrm{kg}^{-1}$, respectivamente.

A determinação do teor total de arsênio nos digeridos indicou a presença desse contaminante em alguns compartimentos, o que provavelmente pode ocasionar a liberação do elemento no ambiente ou na dieta humana, sendo uma potencial fonte de contaminação da cadeia alimentar. Pode-se também observar que os teores de arsênio variaram significativamente nas amostras de ração e que o contaminante foi encontrado principalmente nas amostras que intercalam o ciclo, como as rações de crescimento, postura e engorda e, eventualmente, pela utilização do estimulante nessa fase da produção.

Afirmações mais conclusivas somente poderiam ser emitidas a partir da análise de um número maior de amostras e da especiação química de arsênio nos vários compartimentos investigados. No atual estágio dessa investigação não é possível fazer nenhuma inferência sobre possíveis implicações para a saúde humana.

\section{AGRADECIMENTOS}

À Coordenação de Aperfeiçoamento de Pessoal de Nível Superior (CAPES) e ao Conselho Nacional de Desenvolvimento Científico e Tecnológico $(\mathrm{CNPq})$ pelas bolsas concedidas. Os autores também são gratos à Fundação de Amparo à Pesquisa do Estado de São Paulo (FAPESP) pelos financiamentos obtidos.

\section{REFERÊNCIAS}

1. Azevedo, F. A.; Chasin, A. A. M.; Metais: Gerenciamento da Toxicidade, Ed. Atheneu: São Paulo, 2003, cap. 8.

2. http://www.ubabef.com.br, acessada em Outubro 2010.

3. Hilleman, B.; Chem. Eng. News 2007, 85, 34.

4. Devesa, V.; Velez, D.; Montoro, R.; Food Chem. Toxicol. 2008, 46, 1.

5. Aleixo, P. C.; Dissertação de Mestrado, Universidade Federal de São Carlos, Brasil, 2000.

6. Welz, B.; Sperling, M.; Atomic Absorption Spectrometry, $3^{\text {rd }}$ ed., Weinheim, Wiley: New York, 1999.

7. Vandecasteele, C.; Block, C. B.; Modern Methods for Trace Element Determination, John Wiley \& Sons: Chichester, 1993.

8. Husáková, L.; Cernohorský, T.; Srámková, J.; Vavrusová L.; Food Chem. 105, 286, 2007.

9. Frank, J.; Krachler, M.; Shotyk, W.; Anal. Chim. Acta 2005, 530, 307.

10. Huang, J.; Goltz D.; Smith, F.; Talanta 1988, 35, 907.

11. Chappell, J.; Chiswell, B.; Olszowy, H.; Talanta 1995, 42, 323.

12. Serafimovski, I.; Karadjova, I. B.; Stafilov, T.; Tsalev, D. L.; Microchem. J. 2006, 83,55 .

13. Liu, Z.; Sun, H.; Shen, S.; Li, L.; Shi, H.; Anal. Chim. Acta 2005, 550, 151.

14. Li, X.; Jia, J.; Wang, Z. H.; Anal. Chim. Acta 2006, 560, 153.

15. Shah, A. Q.; Kazi, T. G.; Arain, M. B.; Jamali, M. K.; Afridi, H. I.; Jalbani, N.; Kandhro, G. A.; Baig, J. A.; Sarfraz, R. A.; Ansari, R.; Food Chem. 2009, 113, 1351.

16. Araújo, J. S.; Oliveira, V.; Braga, G. C.; Ciência Animal Brasileira 2007, 8,59 . 